\title{
Application of inverse gas chromatography to the measurement of diffusion and phase equilibria in polyacrylate-solvent systems
}

\author{
Funda Tihminlioglu ${ }^{\mathrm{a}}$, Ronald P. Danner ${ }^{\mathrm{b}, *}$ \\ azmir Institute of Technology, Gaziosmanpasa Bulv. No 16 Cankaya, Izmir, Turkey \\ ${ }^{\mathrm{b}}$ Pennsylvania State University, Center for the Study of Polymer-Solvent Systems, Chemical Engineering Department, University Park, \\ PA 16802, USA
}

\begin{abstract}
The inverse gas chromatography technique (IGC) was used to determine the partition and diffusion coefficients of ethyl acetate and 2-ethylhexyl acrylate in polyacrylate for both infinite dilution and finite concentrations of solvent. Experiments were performed over a temperature range of 60 to $100^{\circ} \mathrm{C}$, more than $100^{\circ} \mathrm{C}$ above the glass transition temperature of the polymer. The capillary column IGC model previously developed for determining partition and diffusion coefficients of infinitely dilute solvent has been modified to account for the concentration of the solvent in the polymer phase. Thermodynamic data obtained from retention theory and the modified capillary column IGC model are compared. (C) 1999 Elsevier Science B.V. All rights reserved.
\end{abstract}

Keywords: Inverse gas chromatography; Diffusion coefficients; Partition coefficients; Thermodynamic parameters; Ethyl acetate; Ethylhexyl acrylate; Polymers; Polyacrlyate

\section{Introduction}

Diffusion of solvents and monomers in rubbery materials is of importance in numerous cases where rubbers are kept in close contact with these substances. Information concerning diffusion coefficients is also necessary in many industrial processes such as devolatilization, drying, coating, and painting. To optimize equipment design and operation so as to satisfy health and environmental regulations reliable thermodynamic and transport data of solvents in the polymer are required. Various techniques exist to measure these data for a given polymersolvent system. Among them, the most prominent are gravimetric sorption, piezoelectric sorption, inverse

*Corresponding author. Tel.: +1-814-865-2574; fax: 1-814-8657846. gas chromatography, NMR, and light scattering techniques. Most of the data in the high polymer concentration region have been obtained using gravimetric sorption and, more recently, inverse gas chromatography (IGC). IGC is a fast, reliable technique that has been applied both above and below the glass transition temperature of the polymer [13]. Sorption methods also provide reliable data, but measurements take a long time and the method cannot be used at the very low concentrations available with IGC.

Although an extensive literature exits on the application of IGC to the infinite dilute solvent region, only a few articles discuss the extension of the method to finite concentrations and then, with one exception [4], only thermodynamic behavior is analyzed. A number of different chromatographic techniques have been used to measure the equilib- 
rium properties at finite concentration: frontal analysis, frontal analysis by characteristic point, elution by characteristic point, elution on a plateau, and elution of an isotope on a plateau. Conder and Young [4] give a detailed and comprehensive discussion of each of these techniques. Elution on a plateau has been used by many researchers for thermodynamic measurements because this technique does not rely on detector calibration and the analysis is very similar to that of infinitely dilute measurements [6-11]. These efforts have focused on the thermodynamic properties of the system. Previously only Tihminlioglu et al. [5] have reported obtaining diffusion coefficients using elution on a plateau. In this work this technique has been used to measure partition and diffusion coefficients for polyacrylate-ethyl acetate and polyacrylate-2-ethylhexyl acrylate systems at infinitely dilute and finite concentrations of the solvent.

\section{Experimental}

Fig. 1 is a schematic of the experimental apparatus. The apparatus is a modified form of that used by Price and Guillet [6]. A Varian gas chromatogram (model 3400) equipped with a thermal conductivity detector, a flame ionization detector, an on column injector, and a circulating air oven was used. For the infinite dilute solvent case, the carrier gas is fed directly to the capillary column and a small amount of solvent is injected.

In the case of finite concentration IGC a uniform background concentration of the solvent is established in the carrier gas. The carrier gas is diverted to the saturator and then passes through a diffuser in the well-stirred, temperature-controlled liquid bath. It leaves the saturator with its equilibrium vapor pressure in the carrier gas. Precise control of the temperature bath is needed in order to obtain a constant plateau concentration. Upon leaving the saturator the gas flows through heated tubing to the injector block and then to the column. As in the infinite dilute case a small pulse of the solvent is then injected. This technique is known as elution on a plateau. By modeling the response peak as described below the partition and diffusion coefficients are determined.

The polyacrylate used had a density of $0.90 \mathrm{~g} / \mathrm{cm}^{3}$ and a glass transition temperature of $-50^{\circ} \mathrm{C}$. Since the experiments were done well above the glass transition of the polymer, the polymer was in rubbery form. The polyacrylate polymer was supplied by the 3M company (St. Paul, MN, USA). The solvents ethyl acetate and 2-ethylhexyl acrylate were obtained from Aldrich (99.9\%, HPLC grade).

For the ethyl acetate system a capillary column with a film thickness of $7 \mu \mathrm{m}$ was used and for the

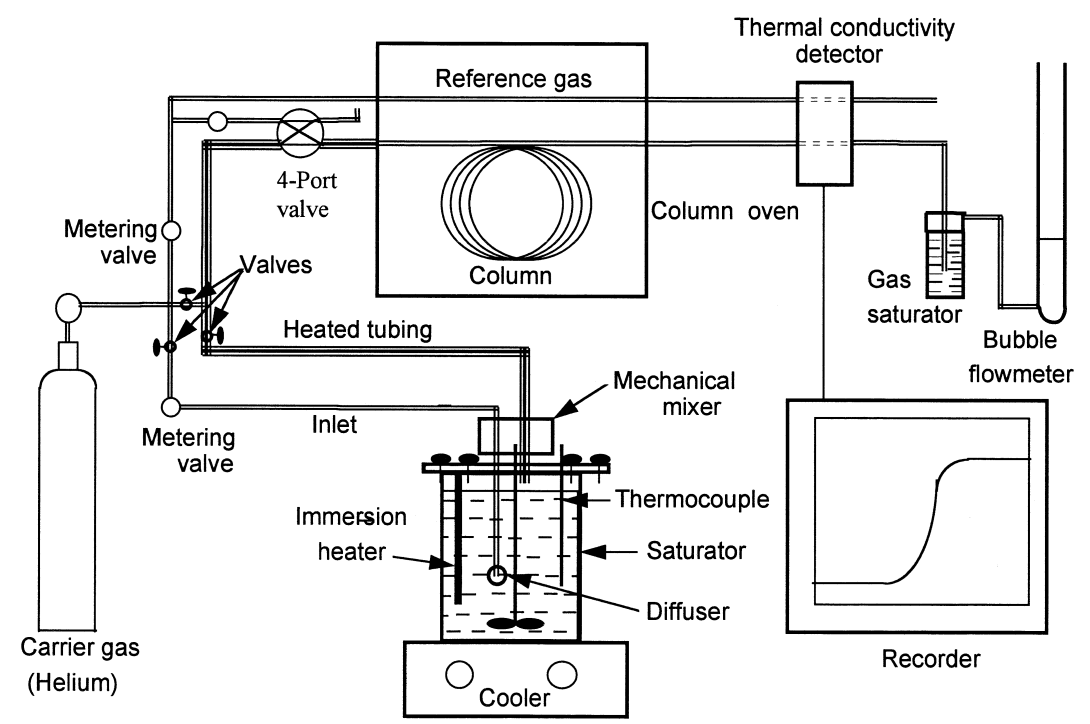

Fig. 1. Schematic of the experimental set up. 
2-ethylhexyl acrylate case the thickness was $1 \mu \mathrm{m}$. The small film thickness was dictated by the low diffusion coefficient of the 2-ethylhexyl acrylate. Both columns had an inside diameter of $530 \mu \mathrm{m}$ and a length of $15 \mathrm{~m}$. The capillary columns were made by Restek (Bellefonte, PA, USA) using the static method of Grob [12].

\section{Theoretical analysis}

The method of analyzing the response from a capillary column for an infinitely dilute input pulse has been presented by Pawlisch and coworkers [2,3] and Arnould and Laurence [13]. The model needs to be modified only slightly to account for the plateau concentration, $C_{\text {plateau. }}$. The equation of continuity for the solute in the gas phase can be written as

$$
\frac{\partial C}{\partial t}+u \frac{\partial C}{\partial z}+C \frac{\partial u}{\partial z}=D_{\mathrm{g}} \frac{\partial^{2} C}{\partial z^{2}}+\frac{2 D_{\mathrm{p}}}{R}\left(\frac{\partial C^{\prime}}{\partial r}\right)_{r=R}
$$

Here $C$ and $C^{\prime}$ are the gas phase and stationary phase solute concentrations, $z$ and $r$ are the axial and radial coordinates, $D_{\mathrm{p}}$ and $D_{\mathrm{g}}$ are the diffusion coefficients for the polymer and gas phases, and $u$ is the mean velocity of the carrier gas. The last term on the left side of Eq. (1) represents the variation of mobile gas velocity caused by the sorption effects associated with the concentration pulse. Disturbances in solute concentration along the column are necessarily accompanied by the changes in the velocity of the mobile phase. This occurs because sorbed solute advances only through the mobile phase; and thus, the total flux of solute and carrier gas molecules must be greater where the amount sorbed is higher.

The total mass balance (solute + carrier gas) gives:

$C_{\text {total }} \frac{\partial u}{\partial z}=\frac{2 D_{\mathrm{P}}}{R} \cdot\left(\frac{\partial C^{\prime}}{\partial r}\right)_{r=R}$

The mole fraction of solute in the gas phase is given by

$y=\frac{C}{C_{\text {total }}}$

Using Eqs. (2) and (3), Eq. (1) reduces to $\frac{\partial C}{\partial t}+u \cdot \frac{\partial C}{\partial z}=D_{\mathrm{g}} \frac{\partial^{2} C}{\partial z^{2}}+\frac{2 D_{\mathrm{p}}(1-y)}{R}\left(\frac{\partial C^{\prime}}{\partial r}\right)_{r=R}$

and for the polymer phase

$\frac{\partial C^{\prime}}{\partial t}=D_{\mathrm{P}} \cdot\left[\frac{1}{R} \frac{\partial}{\partial r}\left(\frac{r \partial C^{\prime}}{\partial r}\right)\right]$

The appropriate initial and boundary conditions are:

$$
\begin{aligned}
& \frac{\partial C}{\partial r}=0 \quad \text { at } r=0 \\
& C(r, z, t)=C_{\text {plateau }} \text { at } t=0, z>0 \\
& C^{\prime}(r, z, t)=\int_{0}^{C_{\text {plateau }}} \frac{\partial C^{\prime}}{\partial C} \mathrm{~d} C \text { at } t=0, z>0 \\
& C(z, t)=C_{\text {plateau }}+C_{\mathrm{o}} \delta(t) \text { at } z=0, t=0 \\
& \frac{\partial C^{\prime}}{\partial r}=0 \text { at } r=R+\tau
\end{aligned}
$$

Here $C_{\mathrm{o}}$ is the strength of solvent pulse injected, $\delta(t)$ is the Dirac function, $R$ is the inner radius of the coated film, and $\tau$ is the thickness of the polymer coating. The boundary conditions can be made dimensionless as follows.

$$
\begin{aligned}
& Y=\frac{\left(C-C_{\text {plateau }}\right) L}{C_{0} u} \\
& X=\frac{z}{L} \quad \theta=\frac{u t}{L} \quad \eta=\frac{r-R}{\tau}
\end{aligned}
$$

The value of $\eta$ is bounded between zero and one within the polymer film.

$$
\begin{aligned}
& Y=q=0 \quad \text { at } \theta=0 \\
& \frac{\partial q}{\partial \eta}=0 \quad \text { at } \eta=1 \\
& Y=\delta(\theta) t_{\mathrm{c}} \quad \text { at } X=0 \\
& Y=q \quad \text { at } \eta=0 \\
& q=\frac{\left[C^{\prime}-\int_{0}^{C_{\text {plateau }}}\left(\frac{\partial C^{\prime}}{\partial C}\right) \mathrm{d} C\right] L}{C_{\mathrm{o}}\left(\frac{\partial C^{\prime}}{\partial C}\right)_{\text {plateau }} u}
\end{aligned}
$$


Thus, Eqs. (4) and (5) become

$$
\begin{aligned}
& \frac{\partial Y}{\partial \theta}+\frac{\partial Y}{\partial X}-\frac{\Gamma \partial^{2} Y}{\partial X^{2}}=\frac{2}{\alpha \beta^{2}} \cdot\left(\frac{\partial q}{\partial \eta}\right)_{\eta=0} \\
& \frac{\partial q}{\partial \theta}=\frac{1}{\beta^{2}} \cdot \frac{\partial q^{2}}{\partial \eta^{2}}
\end{aligned}
$$

At the exit of the column, the dimensionless equation for the response peak in the Laplace domain is

$$
\begin{aligned}
& \frac{C L}{C_{\mathrm{O}} u}=\exp \left(\frac{1}{2 \Gamma}\right) \\
& \quad \times \exp \left[-\left(\frac{1}{4 \Gamma^{2}}+\frac{S}{\Gamma}+\frac{2 \sqrt{ } S}{\alpha \beta \Gamma} \tanh (\beta \vee S)\right)^{1 / 2}\right]
\end{aligned}
$$

where

$$
\Gamma=\frac{D_{\mathrm{g}}}{u L} \quad \alpha=\frac{R}{K(1-y) \tau} \quad \beta^{2}=\frac{\tau^{2}}{D_{\mathrm{p}} t_{\mathrm{c}}}
$$

Here $\tau$ is the thickness of the polymer film, $K$ is equal to $\mathrm{d} C^{\prime} / \mathrm{d} C$ (which for the infinitely dilute case equals $C^{\prime} / C$, the partition coefficient, $K_{\mathrm{P}}$ ), $S$ is the Laplace operator, and $D_{\mathrm{g}}$ and $D_{\mathrm{p}}$ are the gas phase and polymer phase diffusion coefficients. The elution profile is a function of the three dimensionless parameters, $\alpha, \beta$ and $\Gamma$. $\alpha$ is inversely related to the partition coefficient, $\beta^{2}$ is similarly related to the polymer diffusion coefficient, and $\Gamma$ varies proportionately with the gas phase diffusion coefficient. In other words, the parameter $\alpha$ is a thermodynamic parameter while $\beta$ and $\Gamma$ represent the polymer and gas phase transport properties. $y$ is the true mole fraction obtained by correcting for the gas phase nonideality and for compressibility effects due to the pressure gradient in the column $[4,6]$. The concentration in the polymer phase is obtained by integrating the $\mathrm{d} C^{\prime} / \mathrm{d} C$ values from zero concentration to the concentration of interest. The ratio $C^{\prime} / C$ is then the partition coefficient obtained from the capillary column (CCIGC) model.

In Eq. (20) the outlet concentration profile from the gas chromatogram is made dimensionless with the inlet concentration and the carrier gas retention time. The experimental data are regressed using Eq. (20) to obtain the partition and diffusion coefficients. A fast Fourier inverse transform is used to invert the solution of the CCIGC model from the Laplace domain to the time domain. A nonlinear regression to minimize the error between the experimental data and model predictions is carried out using the Levenberg-Marquardt algorithm. The first and the second moments of the elution profile are used to get initial estimates of $\left(\mathrm{d} C^{\prime} / \mathrm{d} C\right)$ and $D_{\mathrm{p}}$ for the regression. Surana et al. [14] have examined the range of applicability of this model. It is recommended that the $\beta$ values should lie between 0.03 and 5.0 in order to obtain reliable results.

Eq. (20) is identical to that derived by Pawlisch and coworkers [2,3] and Arnould and Laurence [13] except for the addition of the $(1-y)$ term in the $\alpha$ parameter. This term accounts for the change in the velocity with concentration., i.e., the sorption effect [5]. The $y$ parameter is equal to zero at infinite dilution conditions.

Theoretical relationships that were developed by Conder and Young [4] and Price and Guillet [6] are used to calculate the retention volumes and sorption isotherms. The retention volume, $V_{\mathrm{N}}$, is given by the expression

$$
V_{\mathrm{N}}=V_{\mathrm{s}}(1-y) \frac{\mathrm{d} C^{\prime}}{\mathrm{d} C}
$$

Here $V_{\mathrm{N}}$ is net retention volume and $V_{\mathrm{s}}$ is the volume of the stationary phase. By integrating Eq. (22) and introducing the mass of polymer used, $W$, the concentration of the solvent in the polymer phase, $Q$, can be found.

$Q=\frac{j}{W} \int_{0}^{C} \frac{V_{\mathrm{N}}}{(1-y)} \mathrm{d} C$

Here $j$ is the pressure drop correction factor [4,5].

To determine an isotherm, retention volumes were measured for a series of solute concentrations. Evaluation of the integral was done by fitting a polynomial to the data and then integrating.

The Flory-Huggins interaction parameter can be calculated from the equilibrium pressure, the vapor pressure, the second virial coefficient, and the volume fractions in the polymer phase. 
$\frac{P_{1}}{P_{1}^{0}} \exp \left[\frac{B_{11}\left(P_{1}-P_{1}^{\mathrm{o}}\right)}{R_{\mathrm{g}} T}\right]=\Phi_{1} \exp \left(\Phi_{2}+\chi \Phi_{2}^{2}\right)$

\section{Results and discussion}

\subsection{Infinitely dilute region}

Experiments were done initially using injection pulses varying between 0.005 and $0.02 \mu \mathrm{l}$. Within experimental error, the same values of the partition coefficient, $K_{\mathrm{p}}$, and the diffusivity, $D_{\mathrm{p}}$, were obtained in each case, indicating that the results were independent of the amount injected and that the solute elution occurred at essentially infinite dilution.

Some results for the polyacrylate-2-ethylhexyl acetate system at $60^{\circ} \mathrm{C}$ are shown in Fig. 2. Two sets of experimental data for two different injection sizes are indicated by the open circles while the model fit resulting from Eq. (20) is shown as the continuous curve. Fig. 2 is typical of the results found in the infinitely dilute systems. The values at a mass fraction of zero in Table 1 are the infinitely dilute partition and diffusion coefficients obtained for this system from 60 to $100^{\circ} \mathrm{C}$. It was because of the large partition coefficients and small diffusivities that a capillary column with only a $1-\mu \mathrm{m}$ thick coating was used. With a thick coating the resulting peaks would be spread out with lower peak heights, which would introduce error in the analysis.

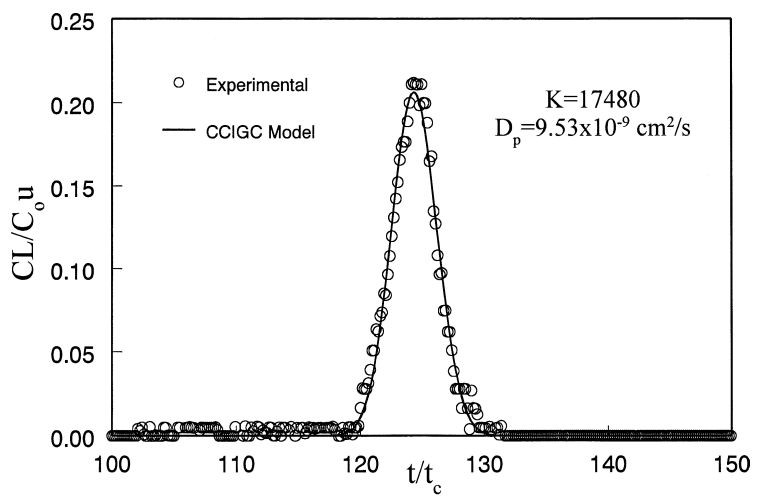

Fig. 2. Comparison of experimental data and CCIGC model for the polyacrylate-2-ethylhexyl acrylate system at $60^{\circ} \mathrm{C}$.
Table 1

Finite concentration data for polyacrylate-2-ethylhexyl acrylate system

\begin{tabular}{llll}
\hline$T\left({ }^{\circ} \mathrm{C}\right)$ & $\omega$ & $K_{\mathrm{P}}$ & $D_{\mathrm{p}}\left(\mathrm{cm}^{2} / \mathrm{s}\right)$ \\
\hline 60 & 0 & 17480 & $9.53 \cdot 10^{-9}$ \\
70 & 0 & 9490 & $1.28 \cdot 10^{-8}$ \\
80 & 0 & 5550 & $2.62 \cdot 10^{-8}$ \\
& 0.005 & 5450 & $3.12 \cdot 10^{-8}$ \\
& 0.011 & 5490 & $3.04 \cdot 10^{-8}$ \\
& 0.020 & 5550 & $1.63 \cdot 10^{-8}$ \\
& 0.038 & 5730 & $2.45 \cdot 10^{-8}$ \\
90 & 0.071 & 6160 & $2.81 \cdot 10^{-8}$ \\
100 & 0 & 3410 & $4.30 \cdot 10^{-8}$ \\
& 0 & 2110 & $5.38 \cdot 10^{-8}$ \\
& 0.004 & 1950 & $8.26 \cdot 10^{-8}$ \\
& 0.008 & 1970 & $1.07 \cdot 10^{-7}$ \\
& 0.013 & 2010 & $1.46 \cdot 10^{-8}$ \\
& 0.022 & 2050 & $3.86 \cdot 10^{-8}$ \\
& 0.036 & 2140 & $6.86 \cdot 10^{-8}$ \\
& 0.053 & 2240 & $2.62 \cdot 10^{-8}$ \\
& 0.076 & 2390 & $6.48 \cdot 10^{-8}$ \\
\hline
\end{tabular}

Table 2

Finite concentration data for polyacrylate-ethyl acetate system

\begin{tabular}{|c|c|c|c|}
\hline$T\left({ }^{\circ} \mathrm{C}\right)$ & $\omega$ & $K_{\mathrm{P}}$ & $D_{\mathrm{p}}\left(\mathrm{cm}^{2} / \mathrm{s}\right.$ \\
\hline \multirow[t]{6}{*}{60} & 0 & 85.8 & $8.05 \cdot 10^{-7}$ \\
\hline & 0.030 & 96.9 & $1.18 \cdot 10^{-6}$ \\
\hline & 0.039 & 101.1 & $1.03 \cdot 10^{-6}$ \\
\hline & 0.066 & 117.3 & $1.04 \cdot 10^{-6}$ \\
\hline & 0.098 & 137.3 & $7.30 \cdot 10^{-7}$ \\
\hline & 0.129 & 157.3 & $3.66 \cdot 10^{-7}$ \\
\hline \multirow[t]{6}{*}{70} & 0 & 61.8 & $1.13 \cdot 10^{-6}$ \\
\hline & 0.028 & 68.6 & $1.40 \cdot 10^{-6}$ \\
\hline & 0.041 & 72.8 & $1.35 \cdot 10^{-6}$ \\
\hline & 0.061 & 80.7 & $1.25 \cdot 10^{-6}$ \\
\hline & 0.082 & 89.2 & $1.22 \cdot 10^{-6}$ \\
\hline & 0.104 & 100.1 & $9.92 \cdot 10^{-7}$ \\
\hline \multirow[t]{6}{*}{80} & 0 & 46.6 & $1.47 \cdot 10^{-6}$ \\
\hline & 0.020 & 49.6 & $2.16 \cdot 10^{-6}$ \\
\hline & 0.027 & 51.2 & $1.50 \cdot 10^{-6}$ \\
\hline & 0.035 & 53.2 & $1.58 \cdot 10^{-6}$ \\
\hline & 0.051 & 57.1 & $1.55 \cdot 10^{-6}$ \\
\hline & 0.080 & 64.4 & $8.79 \cdot 10^{-7}$ \\
\hline 90 & 0 & 35.3 & $1.82 \cdot 10^{-6}$ \\
\hline \multirow[t]{6}{*}{100} & 0 & 27.5 & $2.11 \cdot 10^{-6}$ \\
\hline & 0.015 & 28.6 & $2.06 \cdot 10^{-6}$ \\
\hline & 0.019 & 28.8 & $2.61 \cdot 10^{-6}$ \\
\hline & 0.026 & 29.3 & $1.36 \cdot 10^{-6}$ \\
\hline & 0.033 & 29.9 & $1.13 \cdot 10^{-6}$ \\
\hline & 0.047 & 31.1 & $1.02 \cdot 10^{-6}$ \\
\hline
\end{tabular}


The values of $K_{\mathrm{P}}$ and $D_{\mathrm{p}}$ obtained from the CCIGC model for polyacrylate-ethyl acetate system from 60 to $100^{\circ} \mathrm{C}$ are given in Table 2 in the rows for zero mass fraction. In this case the partition coefficients were much smaller and the diffusion coefficients were larger by several orders of magnitude. Thus, a film thickness of $7 \mu \mathrm{m}$ was suitable.

For both systems the $\ln \left(K_{\mathrm{P}}\right)$ is a linear function of $1 / T$ from 60 to $100^{\circ} \mathrm{C}$ as would be expected for temperatures well above the $T_{\mathrm{g}}$ of the polymer. On this basis, partition coefficients can be predicted at higher and lower temperatures. Fig. 3 illustrates the temperature dependence of the diffusion coefficients for the two systems. The diffusivity of the ethyl acetate is about two orders of magnitude greater than that of 2-ethylhexyl acrylate. The data show little scatter and basic Arrhenius behavior is observed in both cases.

\subsection{Finite concentration region}

Polyacrylate (PA)-ethyl acetate and PA-2ethylhexyl acrylate systems were studied in the same temperature range at finite concentrations up to about $10 \%(\mathrm{w} / \mathrm{w})$ in the polymer. The results for the PA-ethyl acetate system are discussed in detail. For the PA-2-ethyl hexyl acrylate system, only the results are documented.

A typical elution profile observed in the finite concentration cases is shown for the PA-ethyl

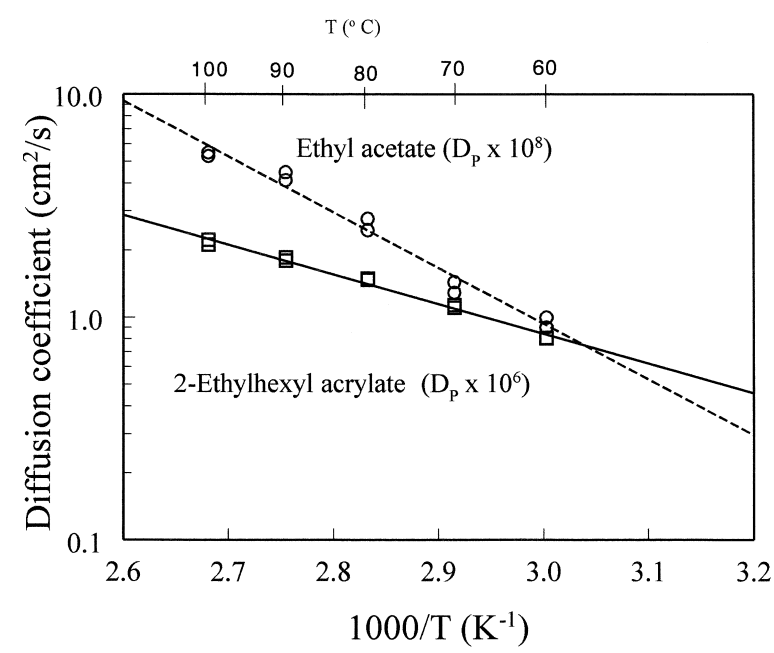

Fig. 3. Temperature dependence of the diffusion coefficients.

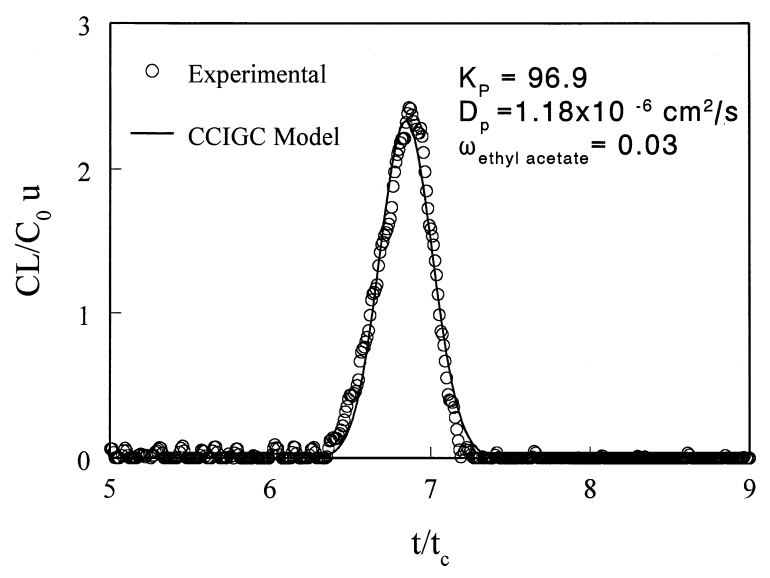

Fig. 4. Finite concentration elution profiles for the polyacrylateethyl acetate system at $60^{\circ} \mathrm{C}$.

acetate system at $60^{\circ} \mathrm{C}$ and a solvent mass fraction in the polymer of 0.030 in Fig. 4. The scatter in the experimental data, which is significantly greater than in the infinitely dilute case, is the result of slight variations in the saturator flow and temperature. Nevertheless, the model reproduces the experimental curve quite well.

The effect of concentration on the diffusivities at 60 and $80^{\circ} \mathrm{C}$ is depicted in Fig. 5. The diffusion coefficients are not strongly dependent upon concentration: they decrease slightly as the mass fraction increases. Iwai et al. [15] have observed the same behavior for the polybutadiene-ethyl benzene and polybutadiene- $n$-nonane systems. The mutual diffusion coefficients of the polyacrylate-ethyl acetate

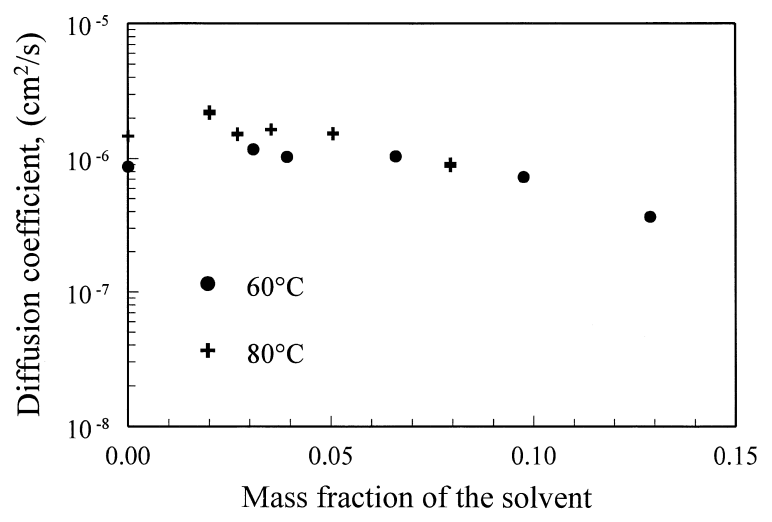

Fig. 5. Finite concentration diffusion data for the polyacrylateethyl acetate system. 


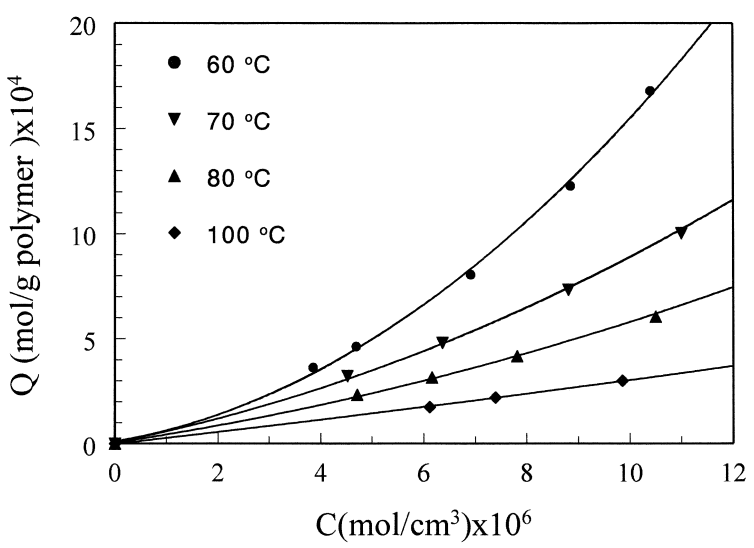

Fig. 6. Absorption isotherms for the PA-ethyl acetate system.

system are much larger than those of most polymersolvent systems. This is because the experiments were carried out at temperatures significantly above the glass transition of the polymer.

To determine the amount of solvent sorbed, Eq. (23) was used. Fig. 6 shows the absorption isotherms for the PA-ethyl acetate system at four different temperatures. The rate of change in concentration of solvent in the polymer phase is greater at lower temperatures and higher concentrations. Fig. 7 shows the partition coefficients for this system as a function of solvent concentration in the gas phase. The solid symbols show the partition coefficients obtained from the finite concentration CCIGC model, and the open symbols show the partition coefficients obtained from the retention volume expression (Eq.

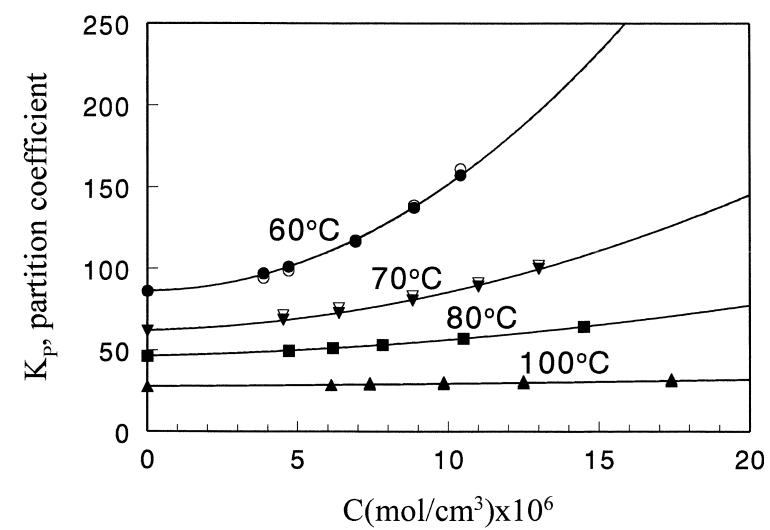

Fig. 7. Partition coefficients for ethyl acetate in PA.

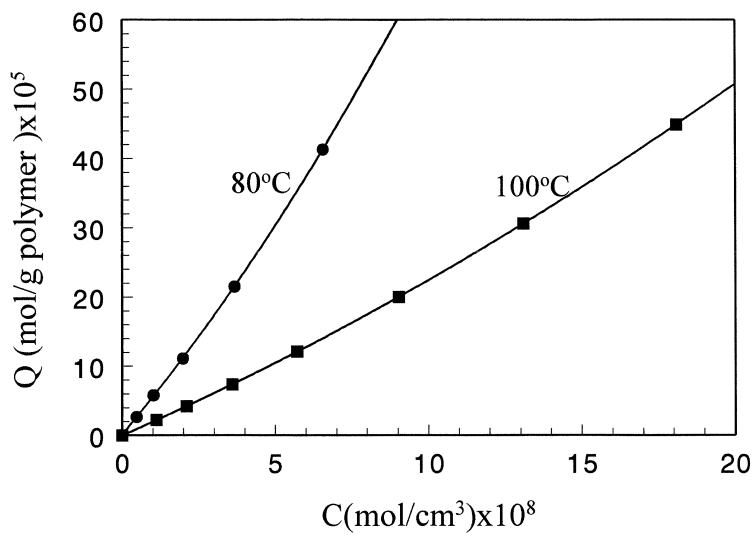

Fig. 8. Absorption isotherms for the PA-2-ethylhexyl acrylate system.

(23)). The results are in good agreement. The curves in this figure are second order polynomial correlations of the experimental data. Table 2 lists the experimental values of the diffusion and partition coefficients.

The finite concentration diffusion partition coefficients for the PA-2-ethylhexyl acrylate system are listed in Table 1. The diffusivity in this system is also not strongly dependent on the concentration. Fig. 8 shows the absorption isotherms at 80 and $100^{\circ} \mathrm{C}$. The graph shows the expected behavior - the concentration of solvent in the polymer phase increases with the solvent concentration in the gas phase and the slope is greater at lower temperatures.

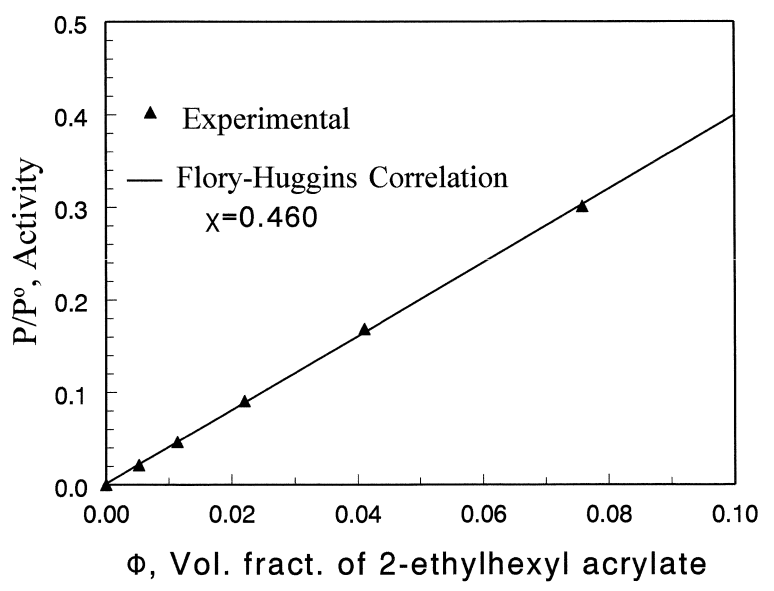

Fig. 9. Flory Huggins correlation for the PA-2-ethylhexyl acrylate system at $80^{\circ} \mathrm{C}$. 
Table 3

Flory-Huggins interaction parameters for the polyacrylate systems

\begin{tabular}{lcc}
\hline System & $T\left({ }^{\circ} \mathrm{C}\right)$ & $\chi$ \\
\hline PA-ethyl acetate & 60 & 1.044 \\
& 70 & 1.040 \\
& 80 & 1.037 \\
PA-2-ethylhexyl acrylate & 100 & 0.936 \\
& 80 & 0.460 \\
& 100 & 0.545 \\
\hline
\end{tabular}

Eq. (24) was used to calculate the Flory-Huggins interaction parameter, $\chi$, as a function of the solvent concentration in the polymer. Fig. 9 shows the correlation for the 2-ethylhexyl acrylate system at $80^{\circ} \mathrm{C}$. The equilibrium data are well described by the Flory-Huggins thermodynamic theory with a constant interaction parameter. The Flory-Huggins interaction parameters for the PA-ethyl acetate and PA-2-ethylhexyl acrylate systems at the measured temperatures are listed in Table 3.

\section{Conclusion}

In summary, the IGC technique is a powerful tool for the determination of diffusion and partition coefficients in both the infinite dilution and finite concentration regions. The finite concentration inverse gas chromatography technique has been used to determine finite concentration partition and diffusion coefficients at a number of temperatures well above the glass transition temperature of the polymer for the polyacrylate-ethyl acetate and polyacrylate2-ethylhexyl acrylate systems. Partition coefficient results obtained by IGC are in good agreement with the values obtained from the retention theory approach. IGC is advantageous since it is a fast and reliable technique. Although the data analysis is somewhat complex, once the procedure has been worked out multiple data points can be obtained much more expediently than with the standard sorption techniques.

\section{Symbols}

$B_{11}$ : second virial coefficient of the pure solvent $\left(\mathrm{cm}^{3} / \mathrm{mol}\right)$
$C$ : solute concentration in the gas phase $(\mathrm{mol} /$ $\mathrm{cm}^{3}$ )

$C^{\prime}$ : solute concentration in polymer phase $(\mathrm{mol} /$ $\mathrm{cm}^{3}$ )

$C_{0}$ : strength of the inlet impulse $\left(\mathrm{mol} \mathrm{s} / \mathrm{cm}^{3}\right)$

$C_{\text {total }}:$ total concentration in the gas phase $(\mathrm{mol} /$ $\mathrm{cm}^{3}$ )

$C_{\text {plateau }}:$ plateau concentration $\left(\mathrm{mol} / \mathrm{cm}^{3}\right)$

$D_{\mathrm{g}}$ : solvent diffusion coefficient in the mobile phase $\left(\mathrm{cm}^{2} / \mathrm{s}\right)$

$D_{\mathrm{p}}$ : solvent diffusion coefficient in the polymer phase $\left(\mathrm{cm}^{2} / \mathrm{s}\right)$

$j:$ pressure drop correction factor

$K$ : slope of sorption isotherm $\left(\mathrm{d} C^{\prime} / \mathrm{d} C\right)$

$K_{\mathrm{P}}$ : equilibrium partition coefficient $\left(C^{\prime} / C\right)$

$L$ : length of the column $(\mathrm{cm})$

$P_{1}$ : column pressure (bar)

$P_{1}^{\mathrm{o}}$ : solvent vapor pressure (bar)

$q$ : dimensionless solute concentration in polymer phase

$Q$ : solvent concentration in the polymer phase (mol/g polymer)

$r$ : radial direction $(\mathrm{cm})$

$R$ : inner radius of the column $(\mathrm{cm})$

$R_{\mathrm{g}}:$ gas constant $(\mathrm{J} / \mathrm{mol}-\mathrm{K})$

$S:$ Laplace operator

$t$ : time (s)

$t_{\mathrm{c}}:$ residence time of the carrier gas $(\mathrm{s})$

$T$ : temperature $(\mathrm{K})$

$T_{\mathrm{g}}$ : glass transition temperature $(\mathrm{K})$

$u$ : mean velocity of the carrier gas $(\mathrm{cm} / \mathrm{s})$

$V_{\mathrm{N}}$ : net retention volume $\left(\mathrm{cm}^{3}\right)$

$V_{\mathrm{s}}$ : volume of the stationary liquid phase $\left(\mathrm{cm}^{3}\right)$

$X$ : dimensionless axial direction

$y$ : mole fraction of solute in the gas phase

$Y$ : dimensionless solute concentration in gas phase

$z$ : axial direction $(\mathrm{cm})$

$W$ : mass of polymer $(\mathrm{g})$

$\alpha$ : dimensionless thermodynamic parameter

$\beta$ : dimensionless polymer phase diffusion parameter

$\Gamma$ : dimensionless gas phase diffusion parameter

$\delta(\mathrm{t}):$ Dirac function $(1 / \mathrm{s})$

$\eta$ : dimensionless radius

$\theta$ : dimensionless time

$\tau$ : film thickness in the capillary column $(\mathrm{cm})$

$\Phi_{\mathrm{i}}$ : volume fraction of the component $\mathrm{i}$ 
$\chi$ : Flory-Huggins polymer-solvent interaction parameter

$\omega_{\mathrm{i}}$ : mass fraction of component $\mathrm{i}$.

\section{References}

[1] I. HadjRomdhane, R.P. Danner, J.L. Duda, Ind. Eng. Chem. Res. 34 (1995) 2536.

[2] C.A. Pawlisch, A. Macris, R.L. Laurence, Macromolecules 20 (1987) 1564.

[3] C.A. Pawlisch, J.R. Bric, R.L. Laurence, Macromolecules 21 (1988) 1685.

[4] J.R. Conder, C.L. Young, Physicochemical Measurements By Gas Chromatography, Wiley, New York, 1979.

[5] F. Tihminlioglu, R.K. Surana, R.P. Danner, J.L. Duda, J. Polym. Sci., Part B: Polym. Phys. 35 (1997) 1279.

[6] G.J. Price, J.E. Guillet, J. Macromol. Sci.-Chem. A23 (12) (1986) 1487.
[7] N.F. Brockmeier, R.W. McCoy, J.A. Meyer, Macromolecules 5 (1972) 130.

[8] N.F. Brockmeier, R.W. McCoy, J.A. Meyer, Macromolecules 5 (1972) 464.

[9] J.R. Conder, J.H. Purnell, Trans. Faraday Soc. 64 (1968) 1505.

[10] J.R. Conder, J.H. Purnell, Trans. Faraday Soc. 64 (1968) 3100 .

[11] J.R. Conder, J.H. Purnell, Trans. Faraday Soc. 65 (1969) 824.

[12] K. Grob, Making and Manipulating Capillary Columns For Gas Chromatography, Springer-Verlag, Heidelberg, 1986.

[13] D.D. Arnould, R.L. Laurence, in: D.R. Lloyd, T.C. Ward, H.P. Shreiber (Eds.), Inverse Gas Chromatography (ACS Symposium Series, No. 391, American Chemical Society, Washington DC, 1989, p. 87.

[14] R.K. Surana, R.P. Danner, F. Tihminlioglu, J.L. Duda, J. Polym. Sci., Part B: Polym. Phys. 35 (1997) 1233.

[15] Y. Iwai, S. Maruyama, S.M. Fujimoto, Y. Arai, Polym. Engn. Sci. 29 (1989) 773. 